\title{
Morphometric Study of Foramen Magnum and Variation in Its Shape
}

\author{
Keshav Krishna ${ }^{1}$, Alka Rashmi $\mathrm{Nag}^{2}$, Renu Prasad ${ }^{3}$ \\ Junior Residents ${ }^{l, 2}$ Professor And Hod \\ ${ }^{3}$ Department of Anatomy, Rajendra Institute Of Medical Sciences, Ranchi
}

\begin{abstract}
Introduction: Foramen magnum plays an important role as a landmark in the region of skull and spine because it transmits key structures like the lower end of the medulla oblongata, meninges, vertebral arteries and the spinal accessory nerve.

Aims and objectives: Our aim was to provide basic osteometric data of anteroposterior and transverse diameters of foramen magnum and to observe its different shapes.

Materials and methods: Thirty Four (34) adult human skulls of unknown sex were obtained from Department of Anatomy, RIMS, Ranchi. Foramen magnum diameters were calculated using sliding vernier calipers and shapes were visually assessed.

Observations and results: Maximum anteroposterior diameter of foramen magnum was found to be $41.5 \mathrm{~mm}$ and minimum was $28.5 \mathrm{~mm}$ with the mean of $34.06 \mathrm{~mm}$ whereas Maximum transverse diameter was $35 \mathrm{~mm}$ and minimum was $22 \mathrm{~mm}$ with the mean of $27.83 \mathrm{~mm}$. Percentage of foramen magnum shapes were as follows: oval $58.8 \%$, Tetragonal $17.6 \%$, hexagonal $11.8 \%$, circular $8.82 \%$ and irregular $2.94 \%$ cases.

Conclusion: Knowledge of dimensions of foramen magnum is important for radiologist, orthopaedicians and neurosurgeons, while planning and performing cranio-vertebral junction surgeries.
\end{abstract}

Key words: Foramen magnum, skull, morphometry, shape, variation.

\section{Introduction}

Foramen magnum is the large opening at the lower part of the occipital bone and transmits key structures like the lower end of the medulla oblongata, meninges, vertebral arteries and the spinal accessory nerve ${ }^{1}$. The foramen magnum in apes and in humans is formed by the fusion of the four individual parts of the occipital bone (pars squama, left and right pars lateralis, and pars basilaris) ${ }^{2}$. Studies comparing the shape of human foramen magnum with other primates have been done earlier ${ }^{3}$.The position of the foramen magnum in humans is unique compared to other mammals. In humans it has migrated well forward in the occipital bone from the back of the skull, to a position beneath the center mass of the skull and brain ${ }^{4}$. It is of particular interest for anthropology, anatomy, forensic medicine and other medical fields. The knowledge of foramen magnum diameters is needed to determine some malformations such as Arnold Chiari syndrome, which shows expansion of transverse diameter ${ }^{5}$. The dimensions of the foramen magnum are important prior to the cutting off of the foramen magnum lesions or posterior cranial fossa lesions, because more the antero-posterior diameter, greater is the contralateral exposure ${ }^{6}$. The diameters and area of the foramen magnum are greater in males than in females, hence its dimensions can be used to determine sex in the medicolegal conditions, especially in the following circumstances, such as explosions, aircraft accidents and war fare injuries ${ }^{5,7}$

\section{Aims And Objectives}

Our aim was to provide basic osteometric data of anteroposterior and transverse diameters of foramen magnum and to observe its different shapes

\section{Materials And Methods}

- Thirty Four (34) adult human skulls of unknown age and sex were obtained from Department of Anatomy, RIMS, Ranchi and studied. Deformed samples were excluded.

- The samples were visually assessed for shape of foramen magnum and were photographed(Fig.no.2) Foramen magnum was classified into five shapes - oval, round, irregular, tetragonal and hexagonal.

- Two bony land marks were determined. Basion i.e. the median point of the anterior margin of foramen magnum \& Opisthion i.e. median point of posterior margin of foramen magnum.

- Anteroposterior diameter (APD) was calculated as distance between these two points.

- Transverse diameter (TD) was measured as a length of line drawn perpendicular to the previous line at the site of maximum curvature of the lateral margins.(Fig.No.1)

- Measurements were taken using the Vernier caliper and measured to the nearest millimeter. 
- All the observations were taken by two observers, using the predetermined methodology to minimize, inter observer \& intra observer error.

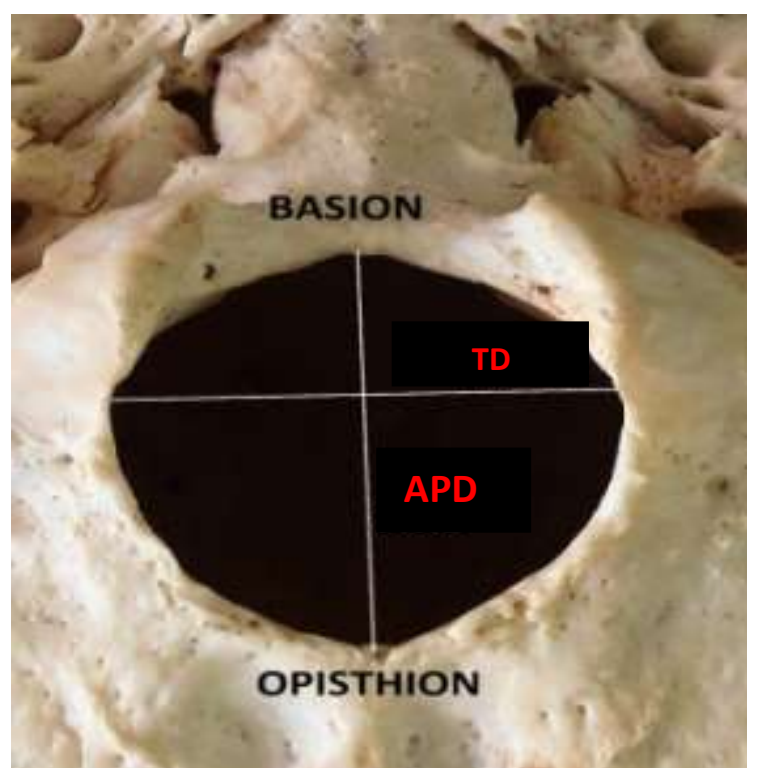

Fig.No. 1: Showing Measurements of Foramen Magnum

II. Statistical Analysis

- All the observations were tabulated in the MS-Excel, (MS Office-2007) format.

- The mean, Median, Mode \& Standard Deviation (SD) for the anteroposterior diameter (APD)and transverse diameter(TD) of foramen magnum were calculated and tabulated - Table no. 1.

- Foramen magnum index (FMI) was calculated using the formula: $\mathrm{FMI}=\mathrm{APD} / \mathrm{TD}$

\section{Observations And Results}

$>$ The various parameters of foramen magnum recorded in dry skulls are represented in Table no.1

$>$ Range of APD -------- $28.5 \mathrm{~mm}$ to $41.5 \mathrm{~mm}$

$>$ Range of TD--------- $22 \mathrm{~mm}$ to $35 \mathrm{~mm}$.

$>$ Mean of APD-----------34.06mm.

$>$ Mean of TD----------27.83mm

$>$ Range of FMI-----------1.01 to 1.47

Specimens having, FMI $\geq 1.2$ were considered to have an oval shape.Their frequencies are shown in Table 2.

$>$ The percentage of different shapes of Foramen magnum is tabulated in Table 3

Table 1: The antero-posterior and transverse diameter of foramen magnum in present study

\begin{tabular}{|l|l|l|}
\hline & & \\
\hline Mean & $\mathbf{3 4 . 0 6}$ & 27.83 \\
\hline Median & 33.75 & 27.75 \\
\hline Mode & 33 & 27.5 \\
\hline $\begin{array}{l}\text { Standard } \\
\text { Deviation }\end{array}$ & 2.53 & 2.6 \\
\hline Minimum & 28.5 & 22 \\
\hline Maximum & $\mathbf{4 1 . 5}$ & 35 \\
\hline
\end{tabular}

Table2: Frequency and percentage of foramen magnum index

\begin{tabular}{|l|l|l|}
\hline & & \\
\hline$<1.20$ & 14 & $\underline{41.17}$ \\
\hline$>=1.20$ & 20 & $\underline{58.82}$ \\
\hline Total & 34 & $\mathbf{1 0 0}$ \\
\hline
\end{tabular}

Table 3: Various shapes of foramen magnum as seen in present study 


\begin{tabular}{|l|l|}
\hline & \\
\hline Oval & $20(58.8 \%)$ \\
\hline Tetragonal & $6(17.6 \%)$ \\
\hline Hexagonal & $4(11.8 \%)$ \\
\hline Circular & $3(8.82 \%)$ \\
\hline Irregular & $1(\underline{2.94 \%})$ \\
\hline
\end{tabular}
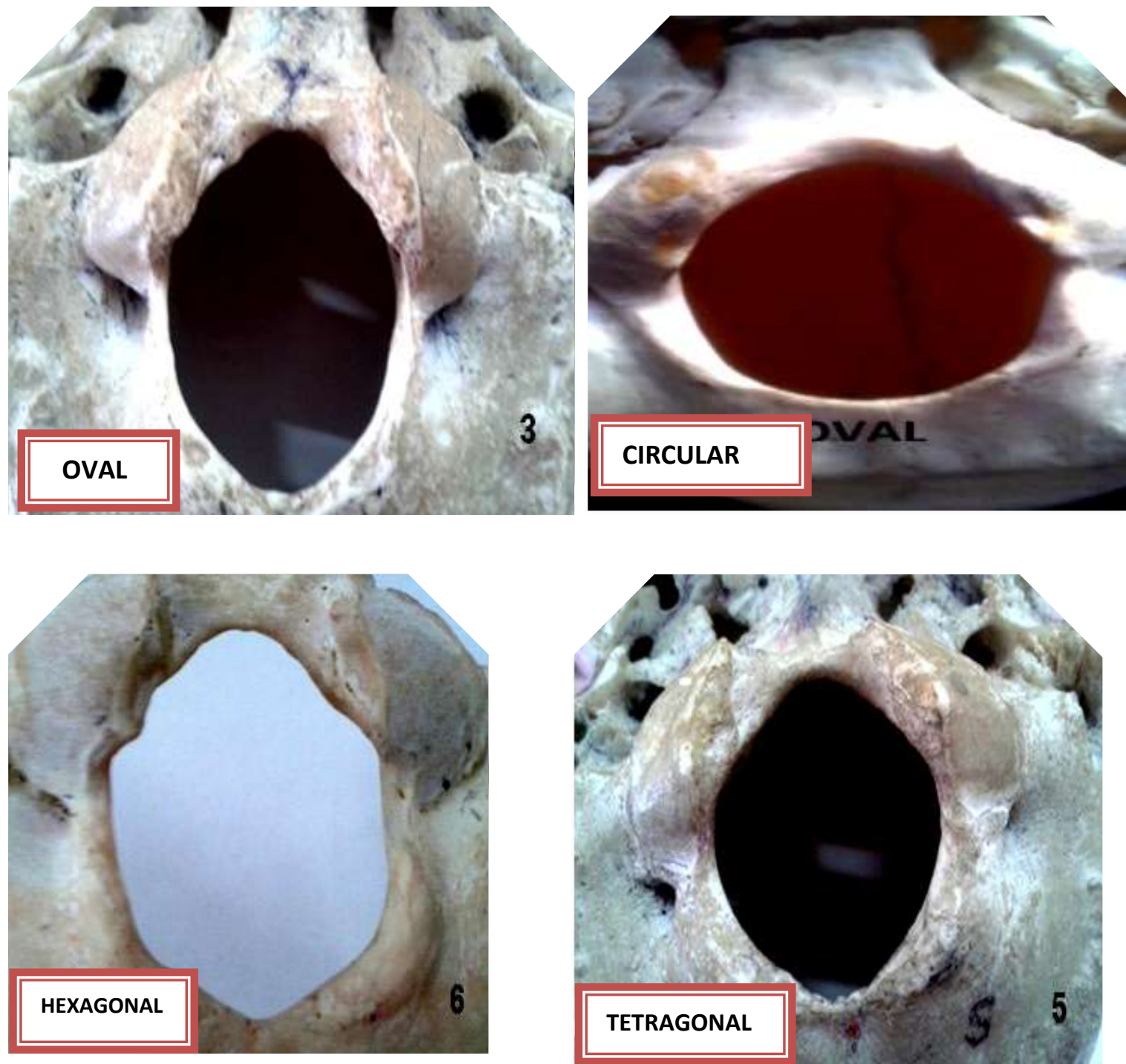

Fig.no.2: Showing various shapes of foramen magnum.

\section{Discussion}

The shape of foramen magnum is considered oval, when FMI $\geq 1.2$. In the present study, the oval shape was most commonly found, as in studies by many other authors. Some authors found round shape as most common. The proportion of different shapes in various studies has been compared in Table 4. Oval shape is associated with difficult surgical approach to the anterior part of foramen magnum. Anteroposterior and transverse diameter of foramen magnum in the present study is compared with those of various authors in Table 5.Abnormal foramen magnum morphometry and shape is associated with various clinical problems. Cerebellar tonsillar herniation is associated with larger anteroposterior diameter ${ }^{8}$. Arnold-Chiari malformation is a condition where anomalous development of occiput causes decreased posterior cranial fossa volume. Basilar invagination is seen. Enlargement of skull base \& cervical canal may develop secondarily ${ }^{9}$. 
Table 4 : Comparison of morphological types of foramen magnum and frequency of occurrence with previous studies

\begin{tabular}{|l|l|l|l|l|l|l|}
\hline $\begin{array}{l}\text { Types of foramen } \\
\text { magnum }\end{array}$ & $\begin{array}{l}\text { Mursh-ed et } \\
\text { al }\end{array}$ & $\begin{array}{l}\text { Radha- } \\
\text { krishanan et al }\end{array}$ & P.Chethan et al & Radhika P.M & $\begin{array}{l}\text { Anil Kumar et al } \\
\text { Present } \\
\text { Study }\end{array}$ \\
\hline Oval & $\mathbf{8 . 1 \%}$ & $\mathbf{3 9 \%}$ & $\mathbf{1 5 . 1 \%}$ & $\mathbf{4 0 \%}$ & $\mathbf{5 0 \%}$ & $\mathbf{5 8 . 8 \%}$ \\
\hline Round & $\mathbf{2 1 . 8 \%}$ & $\mathbf{2 8 \%}$ & $\mathbf{2 2 . 6 \%}$ & $\mathbf{2 0 \%}$ & $\mathbf{2 0 \%}$ & $\mathbf{8 . 8 2 \%}$ \\
\hline Tetragonal & $\mathbf{1 2 . 7 \%}$ & $\mathbf{1 9 \%}$ & $\mathbf{1 8 . 2 \%}$ & $\mathbf{6 \%}$ & $\mathbf{6 \%}$ & $\mathbf{1 7 . 6 \%}$ \\
\hline Hexagonal & $\mathbf{1 7 . 2 \%}$ & - & $\mathbf{5 . 6 \%}$ & $\mathbf{6 \%}$ & $\mathbf{8 \%}$ & $\mathbf{1 1 . 8 \%}$ \\
\hline Irregular & $\mathbf{1 9 . 9 \%}$ & $\mathbf{1 5 . 1 \%}$ & $\mathbf{1 6 \%}$ & $\mathbf{1 6 \%}$ \\
\hline
\end{tabular}

Table 5: Comparison of Antero-posterior Diameter \& Transverse Diameter of various studies

\begin{tabular}{|l|l|l|}
\hline Authors and Year & Antero-posterior diameter (mm) & $\begin{array}{l}\text { Transverse diameter } \\
(\mathbf{m m})\end{array}$ \\
\hline Murshed et al (2003) & 35.9 & 30.45 (Max.) \\
\hline Muthukumar et al (2005) & 33.3 & 27.9 \\
\hline Kizilkant et al (2006) & 34.8 & 29.6 \\
\hline Manoel et al (2009) & 35.4 & 29.85 \\
\hline Suazo, G.et.at (2009) & 36.05 & 30.05 \\
\hline Avci et al (2010) & 34.5 & 29 \\
\hline Tubbs et al (2010) & 31 (Min.) & 27 (Min.) \\
\hline Osun woke et al (2012) & 36.1 (Max.) & 29.5 \\
\hline Radhika.P.M et al (2014) & 35.3 & 29.4 \\
\hline Present study (2016) & 34.06 & 27.83 \\
\hline
\end{tabular}

As per anteroposterior diameter of foramen magnum is considered the finding of present study i.e.34.6mm is close to that of Avci et al(2010),34.5mm and Kizilkant et al( 2006) which was $34.8 \mathrm{~mm}$. The transverse diameter of present study $27.83 \mathrm{~mm}$ is close to Tubbs et al( 2010) $27 \mathrm{~mm}$ and Muthukumar et al( 2005) which was 27.9.

\section{Conclusion}

The present study gives an insight into the variations in morphology and morphometry of foramen magnum \& may be used as a database. Knowledge of its dimensions and variations in its shape are important for radiologist, orthopaedicians and neurosurgeons, while planning and performing cranio-vertebral junction (CVJ) surgeries, to avoid damage to important structures passing through it \& to avert atlanto - occipital instability and hemorrhage ${ }^{10}$.

\section{References}

[1]. Mc Graw Hill Concise Dictionary of Modern Medicine (2002): Mc Graw HillCompanies Inc.

[2]. Avci E, Kara E, Ozturk N C, Uluc K: Anatomical variation of the foramen magnum, occipital condyle and jugular tubercle. Turkish Neurosurgery, 2011;2(2): 181-90.

[3]. Luboga SA, Wood BA: Position and orientation of foramen magnum in higher primates. American Journal of Physical Antvropology, 1990;81: 67-76

[4]. Kimbel WH, Rak Y: The cranial base of Australopithecus afarensis: new insights from the female skull. Phil. Trans. R. Soc. B, 2010; 365: 3365-76.

[5]. Sgouros S, Goldin HJ, Hockely AD, Wake MJ, et al.Intracranial volume change in childhood. JNeurosurg 1999;91:610-616.

[6]. Murshed K A, Cicekeibasi A E, Tuncer I. Morphometric evaluation of the foramen magnum and variations in its shape. A study of computerized tomographic images of normal adults. Tur J Med Sci 2003;33:301-306

[7]. Gunay Y, Altinkok M. The value of the size of foramen magnum in sex determination. J Clin foirensic Med2000;7(3):147-149

[8]. Radhika. P.M, Shailaja shetty, Pratap K.J , C.Sheshgiri, Jyoti K.C, Asian J Med Clin Sci, Ma- Aug 2014, Vol-3, Issue -2, 68-72.

[9]. Standring S, Gray's Anatomy: The Anatomical Basis of Clinical Practice Fortieth Edition, Elsevier Churchill Livingstone, 2008; $415,433,770$

[10]. Muthukumar N, Swaminathan R, Venkatesh G, Bhanumathy SP: A morphometric analysis of the foramen magnum region as it relates to the transcondylar approach. Acta Neurochir (Wien) 147:889-895, 2005 